\title{
Sigma-1 receptor $(\sigma 1 R)$ is downregulated in hepatic malignant tumors and regulates HepG2 cell proliferation, migration and apoptosis
}

\author{
QINGXIA XU $^{1 *}$, LIANG LI $^{1 *}$, CUIHONG HAN $^{1}$, LI WEI $^{1}$, LINGLING KONG $^{2}$ and FANZHONG LIN ${ }^{1}$ \\ ${ }^{1}$ Department of Pathology, Jining First People's Hospital; ${ }^{2}$ Department of Pathology, Basic Science School, \\ Jining Medical University, Jining, Shandong 272111, P.R. China
}

Received June 28, 2017; Accepted December 21, 2017

DOI: $10.3892 /$ or.2018.6226

\begin{abstract}
Sigma-1 receptor ( $\sigma 1 \mathrm{R})$, an important transmembrane structural protein, has been demonstrated to be overexpressed in various types of human cancer, and has been confirmed to be involved in many biological behaviors during tumorigenesis and tumor progression. The aim of the present study was to explore the essential role of o1R in hepatic malignant tumors (HMTs), which, to the best of our knowledge, has not been reported to date. We assessed $\sigma 1 \mathrm{R}$ expression in hepatocellular carcinoma (HCC) tissues and found that o1R was significantly decreased in HCC when compared with that in benign liver tissues $(\mathrm{P}<0.01)$. Additionally, the expression of $\sigma 1 \mathrm{R}$ was shown to be inversely correlated with HCC grade ( $r=-0.424, P=0.021$, Kendall's $\tau$-b-test). We further used a FLAG-SV40-neomycin-plasmid strategy to increase o1R expression in the HepG2 hepatoblastoma cell line. Overexpression of o1R impaired cell proliferation, inhibited cell migration, induced cell cycle arrest at G1 phase, and increased cell apoptosis in vitro. Furthermore, overexpression of $\sigma 1 \mathrm{R}$ decreased the expression levels of STAT-3 and NF- $\kappa \mathrm{B}$, which provided insight into the underlying mechanisms of o1R-associated HMT development and progression. These findings suggest that the decreased expression of o1R plays an essential role in hepatic tumorigenesis, and that it may serve as a potential predictive factor and therapeutic target for the treatment of HMTs.
\end{abstract}

\section{Introduction}

Hepatocellular carcinoma (HCC) and hepatoblastoma (HB) are two common hepatic malignant tumors (HMTs) that

Correspondence to: Professor Fanzhong Lin, Department of Pathology, Jining First People's Hospital, 99 Shixian Road, Jining, Shandong 272111, P.R. China

E-mail: linfanzhong@yahoo.com

\section{*Contributed equally}

Key words: o1 receptor, histological differentiation, proliferation, migration, apoptosis typically occur in adults and children, respectively. HCC originates from hepatocytes, while the origin of $\mathrm{HB}$ is more complex, as it arises from primary hepatoblasts (1). HCC is the most common type of HMT, and results in 10,000 deaths worldwide every year, most of which occur in Asian countries (2). Additionally, the mortality rate of HCC ranks second among all primary cancer-related mortalities, and as many as $90 \%$ of these deaths are related to metastasis $(3,4)$. Viral infection and chronic inflammatory liver diseases are common risk factors for HCC (5). Accurate diagnosis and medical advice in cases of HCC are frequently delayed due to the lack of obvious symptoms in the early stages (6). At present, the methods of diagnosis and treatment for HCC are numerous, but the short survival times of HCC patients indicate the poor prognosis associated with this disease.

Sigma $(\sigma)$ receptors were initially described by Martin et al (7) in 1976 as subtypes of opioid receptors, and have since been reported to have high affinity for many antipsychotic drugs. Pharmacological studies have indicated that there are at least two $\sigma$ receptor subtypes, of which only the $\sigma 1$ receptor $(\sigma 1 \mathrm{R})$ has been cloned. The cloned $\sigma 1 \mathrm{R}$ has 223 amino acids and shares $30 \%$ identity and $67 \%$ similarity with a yeast sterol C8-C7 isomerase $(8,9)$. The o1R gene encodes a $25.3-\mathrm{kDa}$ protein with two putative transmembrane segments, although it remains unclear whether the $\mathrm{N}$ and $\mathrm{C}$ termini are cytoplasmic or extracytoplasmic $(10,11)$.

Pharmacological studies have indicated that o1R binds to a wide range of compounds, including opiates, antipsychotics and neurosteroids. Pentazocine and SKF10047 are two selective agonists for $\sigma 1 \mathrm{R}$ (12). However, endogenous ligands for $\sigma$ receptors have not yet been defined. The function of $\sigma 1 \mathrm{R}$ has been explored by studying its interaction with its ligands. Brent and Pang revealed that certain o1R ligands were potent inhibitors of cell proliferation in human mammary adenocarcinoma, colon carcinoma and melanoma (13). Meanwhile, the o1R ligand SKF10047 was found to be effective at modulating cell proliferation in the metastatic breast cancer cell line MDA-MB-231 (14).

Previous studies have found that $\sigma 1 \mathrm{R}$ is highly expressed in various cancer tissues, including those of neural and non-neural origins (15). Additionally, the upregulation of $\sigma 1 \mathrm{R}$ was reported to correlate with the biological behavior of tumors, 
such as proliferation, adhesion and cell death $(14,16)$. Our previous study showed that o1R was overexpressed in human esophageal squamous cell carcinoma and that the overexpression of $\sigma 1 \mathrm{R}$ was significantly associated with the pathological TNM classification and lymph node metastasis (18). However, the expression of $\sigma 1 \mathrm{R}$ and its biological relevance in $\mathrm{HCC}$ have not yet been identified.

In the present study, we first evaluated the expression status of $\sigma 1 \mathrm{R}$ in $\mathrm{HCC}$, showing that $\sigma 1 \mathrm{R}$ expression was decreased with the progression of $\mathrm{HCC}$ and was significantly correlated with tumor grade. We then increased o1R expression in HepG2 cells using a FLAG-SV40-neomycin-plasmid strategy, which indicated that $\sigma 1 \mathrm{R}$ upregulation impaired cell proliferation and induced cell cycle arrest and cell apoptosis in HepG2 cells. Furthermore, immunoblotting analysis revealed that multiple migration-associated pathways were regulated by $\sigma 1 \mathrm{R}$ upregulation, providing valuable evidence of $\sigma 1 \mathrm{R}$-associated mechanisms in HMT development and progression. Taken together, the present findings strongly suggest a causal relationship between o1R expression and HMT development, indicating that $\sigma 1 \mathrm{R}$ may serve as a potential target in research on the pathogenesis and prognosis of HMT.

\section{Materials and methods}

Materials and cell lines. HepG2 and SMCC-7721 cell lines, which originate from primary hepatoblasts (19) and mature hepatocytes, respectively, were used in the present study. The human HB cell line HepG2 and the HCC cell line SMCC-7721 were obtained from GeneChem Co. Ltd. (Shanghai, China) and cultured in Dulbecco's modified Eagle's medium (DMEM) containing $10 \%$ fetal calf serum (FCS), in an atmosphere of $5 \% \mathrm{CO}_{2}$ at $37^{\circ} \mathrm{C}$. Polyclonal anti-o1R (AP2747A; Abgent, San Diego, CA, USA), anti-NF- $\kappa$ B (8242S; Cell Signaling Technology, Inc., Danvers, MA, USA), anti-STAT-3 (Ab68153; Abcam, Cambridge, UK), and anti- $\beta$-actin (SAB5500001; Sigma-Aldrich ${ }^{\circledR}$ Co. LLC, St. Louis, MO, USA) antibodies were used for immunohistochemistry or western blotting. The peroxidase-conjugated anti-rabbit secondary antibody was purchased from Santa Cruz Biotechnology, Inc. (sc-2004; Santa Cruz, CA, USA).

Specimen collection. For the retrospective analysis, archived formalin-fixed, paraffin-embedded human hepatic tissues from 40 patients were obtained from the Department of Pathology of Jining First People's Hospital between 2012 and 2014. The 40 samples included 30 specimens of HCC and 10 specimens of hepatic cavernous hemangioma $(\mathrm{HCH})$. The HCC patients comprised 26 men and 4 women (median age, 59 years). Information regarding sex, age, stage of disease, and histopathological parameters was retrieved from the medical records, and the patient data are summarized in Table I. All the tumors were confirmed as $\mathrm{HCC}$ by the pathologists at the Clinical Pathology Department of Jining First People's Hospital. In addition, 26 samples of cirrhotic liver tissue, from $\geq 2 \mathrm{~cm}$ away from the tumor edge, were obtained from the $30 \mathrm{HCC}$ patients to represent precancerous lesions. The evaluation of tumor differentiation was based on histological criteria of the WHO Pathological Classification of Tumors guidelines. The study was approved by the Ethics Committee
Table I. Clinical parameters of the HCC patients.

Clinical parameters

No.

$\begin{array}{lr}\text { Age (years) } & \\ \leq 59 & 15 \\ >59 & 14 \\ \text { Sex } & \\ \text { Male } & 25 \\ \text { Female } & 4 \\ \text { Tumor size (cm) } & \\ \leq 3 & 10 \\ 3-5 & 8 \\ >5 & 11\end{array}$

Differentiation

G1

G2

G3

AFP $(\mathrm{ng} / \mathrm{ml})$

$\leq 20$

$>20$

Hepatitis B surface antigen

Negative

Positive

Microvascular invasion

Absent

Present

Tumor number

Single

Multiple

AFP, $\alpha$-fetoprotein; HCC, hepatocellular carcinoma.

of the Central Hospital of Jining, the local ethics committee, and only patients who had provided written informed consent were included.

Immunohistochemical staining. The sections were dewaxed in xylene and rehydrated in a series of graded alcohols. Subsequently, the slides were submerged for $10 \mathrm{~min}$ in a peroxidase quenching solution containing one part $30 \%$ hydrogen peroxide to 9 parts absolute methanol. After rinsing in PBS, antigen retrieval was carried out by autoclaving the tissue in $0.01 \mathrm{M}$ sodium citrate buffer ( $\mathrm{pH} \mathrm{6.0)}$ ) at $120^{\circ} \mathrm{C}$ for 3 min. Following autoclaving, the sections were blocked in $10 \%$ normal goat serum for $10 \mathrm{~min}$ at room temperature, and then incubated overnight at $4{ }^{\circ} \mathrm{C}$ with an anti- $\sigma 1 \mathrm{R}$ polyclonal antibody (1:400; Abgent). Subsequently, the sections were subjected to staining with a 2-Step Plus Poly-HRP Anti-Mouse/Rabbit IgG Detection System (PV-9000; ZSGB-BIO, Beijing, China) and a Liquid DAB substrate kit (Invitrogen, Shanghai, China). Samples were rinsed well with distilled water, then counterstained with Mayer's hematoxylin, dehydrated and mounted.

The immunohistochemical staining results were assigned a mean score considering both the intensity of staining and 
the proportion of tumor cells showing unequivocal positive reactivity. Each section was independently assessed by two histopathologists without prior knowledge of the patient data. Positive reactions were defined as the presence of brown staining in the cell cytoplasm, nucleus and membrane. For $\sigma 1 R$, a staining index (values 0-12) was determined by multiplying the score for staining intensity $(0$, no staining; 1 , weak staining; 2, moderate staining; and 3, strong staining) by the score for the positive stained area (1, positive staining in $0-25 \%$ of tumor cells; 2 , positive staining in $>25-50 \%$ of tumor cells; 3 , positive staining in $51-75 \%$ of tumor cells; 4 , positive staining in $>75-100 \%$ of tumor cells). For the purpose of statistical analyses, scores of 0-4 were considered low expression $(-)$, and scores of 5-12 were considered high expression (+).

Reverse transcription-quantitative PCR (RT-qPCR). Total RNA was extracted and purified from the HepG2 and SMCC-7721 cells using TRIzol reagent (Invitrogen) according to the manufacturer's instructions. RT was performed using a RevertAid First Strand cDNA Synthesis kit (Thermo Fisher Scientific, Inc., Waltham, MA, USA) to obtain cDNA. The expression level of $\sigma 1 \mathrm{R}$ mRNA was measured by RT-qPCR. Primers used were as follows: o1R, 5'-ACCATCATCTCTGGC ACCTTCC-3' (forward), and 5'-GCCAAAGAGGTAGGT GGTGAGC-3' (reverse); $\beta$-actin, 5'-CACCCAGCACAATGA AGATCAAGAT-3' (forward), and 5'-CCAGTTTTTAAATCC TGAGTCAAGC-3' (reverse). PCR amplification consisted of 40 cycles $\left(95^{\circ} \mathrm{C}\right.$ for $15 \mathrm{sec}$ and $60^{\circ} \mathrm{C}$ for $\left.60 \mathrm{sec}\right)$, after an initial denaturation step $\left(95^{\circ} \mathrm{C}\right.$ for $\left.10 \mathrm{~min}\right)$. The relative expression of $\sigma 1 \mathrm{R}$ was normalized to $\beta$-actin mRNA level using the $2^{-\Delta \Delta \mathrm{Cq}}$ method. All samples were examined in triplicate.

Construction of expression vectors and cell transfection. To achieve o1R overexpression, Lentivector Expression Systems (GeneChem, Shanghai, China) were obtained to construct lentiviruses encoding $\sigma 1 \mathrm{R}$, which were then transfected into HepG2 cells. The primers for the o1R gene were as follows: forward, 5'-ACGGGCCCTCTAGACTCGAGCGCCACCATG CAGTGGGCCGTGGGCCG-3'; and reverse, 5'-AGTCAC TTAAGCTTGGTACCGAAGGGTCCTGGCCAAAGAGGT AGG-3'. The designed DNA sequence was inserted into the lentivirus-based GV141 vector (GeneChem) with XhoI/KpnI sites. An empty vector was used as a negative control (NC). For transfection, HepG2 cells were plated into 6-well plates at $2 \times 10^{5}$ cells per well. After $24 \mathrm{~h}$, cells were transfected with the lentivirus expressing $\sigma 1 \mathrm{R}$ or the $\mathrm{NC}$ lentivirus, and then cultured in a $5 \% \mathrm{CO}_{2}$ incubator at $37^{\circ} \mathrm{C}$ for another 3 days. Cells were then harvested and total proteins were extracted to determine the overexpression efficiency by western blotting.

Protein extraction and immunoblotting analysis. The total cellular protein was extracted from cells using $2 \mathrm{X}$ RIPA buffer containing protease inhibitors. The protein concentration was estimated using the Pierce $660 \mathrm{~nm}$ protein assay (Thermo Fisher Scientific, Inc.). Equal amounts of tissue lysates $(50 \mu \mathrm{g})$ were electrophoresed on $12 \%$ polyacrylamide gels at $40 \mathrm{~V}$ for $30 \mathrm{~min}$, followed by $60 \mathrm{~V}$ for $3 \mathrm{~h}$. The lysates were then transferred to polyvinylidene fluoride (PVDF) membranes (EMD Millipore, Bedford, MA, USA). Subsequently, the membranes were blocked in 5\% skim milk in PBS-Tween (0.01 M PBS, 0.05\% Tween-20) for $1 \mathrm{~h}$ at room temperature, followed by the addition of the primary antibody (anti-STAT-3 dilution, 1:1,000; anti-NF- $\mathrm{B}$ dilution, 1:1,000 and anti- $\beta$-actin dilution, 1:2,000, respectively) for $2 \mathrm{~h}$ at room temperature. After that, the membranes were washed and incubated with peroxidase-conjugated anti-rabbit secondary antibodies (dilution, 1:2,000) and analyzed using a Pierce ${ }^{\mathrm{TM}}$ ECL Western Blotting Substrate kit (Thermo Fisher Scientific, Inc.). $\beta$-actin was examined as an internal control in this experiment (dilution, 1:2,000).

MTT assay. Cell viability in the o1R-overexpressing and NC groups was assessed with 3-(4,5-dimethylthiazol-2-yl)diphenyltetrazolium bromide (MTT), which is converted to a colored, soluble formazan product in metabolically active cells. HepG2 cells $\left(5 \times 10^{3}\right)$ were seeded into 96-well plates and incubated for $48 \mathrm{~h}$, after which $10 \mu \mathrm{l}$ of sterile MTT $(5 \mathrm{mg} / \mathrm{ml}$ in PBS, pH=7.4) was added to each well and incubated for $4 \mathrm{~h}$. The medium was then removed from the wells and replaced with $150 \mu$ dimethyl sulfoxide (DMSO) (Amresco Inc., Solon, $\mathrm{OH}, \mathrm{USA}$ )/well, and the absorbance at $490 \mathrm{~nm}$ was measured within $10 \mathrm{~min}$ of DMSO addition. Each experiment was conducted in triplicate.

Cell migration assay. Cell migration was determined by a Transwell migration assay. Cells $\left(5 \times 10^{4}\right)$ were seeded into the top chambers of 24-well Transwell chambers with $8-\mu \mathrm{m}$ micropore membrane filters (Corning Inc., Corning, NY, USA), and the bottom chambers were filled with $0.5 \mathrm{ml} \mathrm{DMEM} / \mathrm{F}-12$ medium with $20 \%$ FBS as a chemoattractant. After $24 \mathrm{~h}$, the non-invaded cells on the upper surface were carefully removed with a cotton swab, and the membranes were fixed and stained with crystal violet reagent. Migration was quantified by counting 3 random fields under a light microscope (magnification, x200). Data obtained from 3 separate chambers were presented as mean values.

Cell cycle analysis. Flow cytometry was used to determine the cell cycle distribution and to detect apoptosis, and was performed as previously described (19). Initially, HepG2 cells $\left(2 \times 10^{5}\right)$ were transfected with GV141-o1R or NC plasmids and incubated at $37^{\circ} \mathrm{C}$ for 4 days. Harvested cells were fixed with $75 \%$ cold ethanol at $4^{\circ} \mathrm{C}$ overnight, washed twice with ice-cold PBS, incubated with $1 \mathrm{mg} / \mathrm{ml} \mathrm{RNase}$ at $37^{\circ} \mathrm{C}$ for $40 \mathrm{~min}$, and stained with propidium iodide (PI; $100 \mu \mathrm{g} / \mathrm{ml}$; GeneChem). The fluorescence of DNA-bound PI in cells was measured with a flow cytometer (FACSCalibur; BD Biosciences, San Jose, CA, USA) and the cell populations in different phases of the cell cycle were analyzed with ModFit 3.0 software (Verity Software House, Inc., Topsham, ME, USA). Each experiment was performed in triplicate.

Annexin V-FITC apoptosis assay. An Annexin V-FITC apoptosis detection kit (KeyGen Biotech, Nanjing, China) was used for the labeling of apoptotic cells, according to the manufacturer's protocol. HepG2 cells $\left(2 \times 10^{5}\right)$ were transfected with o1R-expressing or NC lentiviruses. After incubation for 4 days, the cells were harvested, washed with PBS buffer, and resuspended in $200 \mu \mathrm{l}$ binding buffer. Then, $5 \mu \mathrm{l}$ Annexin V-FITC was added into the cell suspension and 
incubated at room temperature for $15 \mathrm{~min}$. The cell cycle was monitored using PI (50 $\mu \mathrm{g} / \mathrm{ml}$; Sigma-Aldrich Co. LLC) staining of nuclei. Signals were detected with a FACSCalibur flow cytometer (Beckman Coulter, Inc., Brea, CA, USA). All experiments were performed in triplicate.

Statistical analysis. Data are expressed as the mean \pm standard deviation of 3 independent experiments. Differences were compared using a Student's t-test. Associations between $\sigma 1 \mathrm{R}$ expression and clinicopathological characteristics were assessed with the Kendall's $\tau$-b test. All statistical analyses were performed with SPSS 20.0 software (IBM Corp., Armonk, NY, USA). Each P-value is two-tailed, and $\mathrm{P}<0.05$ was considered to indicate a statistically significant difference.

\section{Results}

$\sigma l R$ is decreased in HCC tissues. Immunohistochemical staining was used to examine the expression patterns of $\sigma 1 \mathrm{R}$ in tissue samples from $30 \mathrm{HCC}$ patients, as well as benign liver tissues from $10 \mathrm{HCH}$ patients. From the $30 \mathrm{HCC}$ patients, 29 samples of malignant tumor tissue (after 1 sample was excluded due to extensive necrosis preventing scoring) as well as 26 samples of cirrhotic tissue, representing precancerous lesions, were evaluated. As shown in Fig. 1A, in benign hepatic tissues, the positive signals were intense and well distributed in the cytoplasm, whereas weak to moderately positive signals were observed in precancerous lesions, and weak or negative staining was observed in the tumor tissues. The rates of $\sigma 1 \mathrm{R}^{+}$ expression in benign hepatic tissue, hepatic cirrhosis and HCC specimens were 90 (9/10), 65.38 (17/26) and 27.59\% (8/29), respectively. The difference was statistically significant between benign hepatic tissues and HCC $(\mathrm{P}<0.01)$ (Fig. 1B). Therefore, we concluded that $\sigma 1 \mathrm{R}$ is downregulated in HCC tissues.

olR expression is positively correlated with HCC grade. Immunohistochemical staining was used to explore the expression of o1R in 30 cases of HCC. o1R immunoreactivity, which mainly showed a cytoplasmic staining pattern, was analyzed with respect to various clinicopathological parameters in these cases (Table II). A significant correlation was found between o1R level and the degree of histological differentiation of the tumors $(r=-0.424, \mathrm{P}=0.021)$. Notably, intense staining was more frequent in well-differentiated cases of $\mathrm{HCC}$, and $\sigma 1 \mathrm{R}^{+}$ expression was observed in 50\% of grade I cases and $15.8 \%$ of grade II/III cases (Fig. 2). There were no significant correlations between $\sigma 1 \mathrm{R}$ expression and other clinical parameters.

olR mRNA expression in HepG2 and SMCC-7721 cell lines. The mRNA levels of $\sigma 1 \mathrm{R}$ were assessed in HepG2 and SMCC-7721 cell lines by RT-qPCR. It was observed that $\sigma 1 \mathrm{R}$ mRNA was expressed in the two cell lines, and notably, that the expression level of o1R in SMCC-7721 was $~ 55 \%$ of the level in HepG2 cells (Fig. 3A). As the expression level in HepG2 was higher than that in SMCC-7721, we selected the HepG2 cell line for subsequent experiments.

olR expression is increased efficiently by lentiviral expression vector transfection in HepG2 cells. To investigate the
Table II. Association between $\sigma 1 \mathrm{R}$ expression and clinical pathological parameters in HCC.

\begin{tabular}{|c|c|c|c|c|}
\hline \multirow{2}{*}{$\begin{array}{l}\text { Clinical } \\
\text { parameters }\end{array}$} & \multicolumn{2}{|c|}{$\begin{array}{c}\sigma 1 \mathrm{R} \\
\text { status }^{\mathrm{a}}\end{array}$} & \multirow[b]{2}{*}{$\mathrm{r}^{\mathrm{b}}$} & \multirow[b]{2}{*}{ P-value } \\
\hline & - & + & & \\
\hline \multicolumn{5}{|l|}{ Age (years) } \\
\hline$\leq 59$ & 12 & 3 & 0.176 & 0.427 \\
\hline$>59$ & 9 & 5 & & \\
\hline \multicolumn{5}{|l|}{ Sex } \\
\hline Male & 19 & 6 & 0.201 & 0.552 \\
\hline Female & 2 & 2 & & \\
\hline \multicolumn{5}{|c|}{ Tumor size $(\mathrm{cm})$} \\
\hline$\leq 3$ & 7 & 3 & -0.199 & 0.256 \\
\hline $3-5$ & 4 & 4 & & \\
\hline$>5$ & 10 & 1 & & \\
\hline \multicolumn{5}{|c|}{$\begin{array}{l}\text { Histological } \\
\text { differentiation }\end{array}$} \\
\hline $\mathrm{G} 1$ & 5 & 5 & -0.424 & 0.021 \\
\hline G2 & 7 & 3 & & \\
\hline G3 & 9 & 0 & & \\
\hline \multicolumn{5}{|c|}{ AFP (ng/ml) } \\
\hline$\leq 20$ & 8 & 5 & -0.219 & 0.406 \\
\hline$>20$ & 13 & 3 & & \\
\hline \multicolumn{5}{|c|}{$\begin{array}{l}\text { Hepatitis B } \\
\text { surface antigen }\end{array}$} \\
\hline Negative & 5 & 2 & 0.012 & 1.000 \\
\hline Positive & 16 & 6 & & \\
\hline \multicolumn{5}{|c|}{$\begin{array}{l}\text { Microvascular } \\
\text { invasion }\end{array}$} \\
\hline Absent & 10 & 7 & 0.362 & 0.093 \\
\hline Present & 11 & 1 & & \\
\hline \multicolumn{5}{|c|}{ Tumor number } \\
\hline Single & 19 & 8 & -0.168 & 0.586 \\
\hline Mutiple & 2 & 0 & & \\
\hline
\end{tabular}

${ }^{\mathrm{a}}-$, negative, scores of $0-4 ;+$, positive, scores of 5-12. ${ }^{\mathrm{b}}$ The Kendall's tall-b test; $r$, Kendall tau coefficient value; ${ }^{c}$ Each P-value is two-tailed and significance level is 0.05 . AFP, $\alpha$-fetoprotein; $\sigma 1 \mathrm{R}$, sigma-1 receptor; HCC, hepatocellular carcinoma.

mechanism by which o1R contributes to the malignancy of HMTs, we performed lentiviral-mediated overexpression of $\sigma 1 \mathrm{R}$ in HepG2 cells. The upregulation efficiency of $\sigma 1 \mathrm{R}$ was evaluated by western blot analysis. As shown in Fig. 3B and C, the protein expression level of o1R was significantly upregulated compared with that in the $\mathrm{NC}$ group.

olR overexpression inhibits Hep $\mathrm{G} 2$ cell growth and migration. The effect of $\sigma 1 \mathrm{R}$ overexpression on the proliferative ability of HepG2 cells was determined by MTT assay. As illustrated in Fig. 4A, the cellular proliferative rate of the o1R-GV141 group was markedly reduced from the first day compared with 

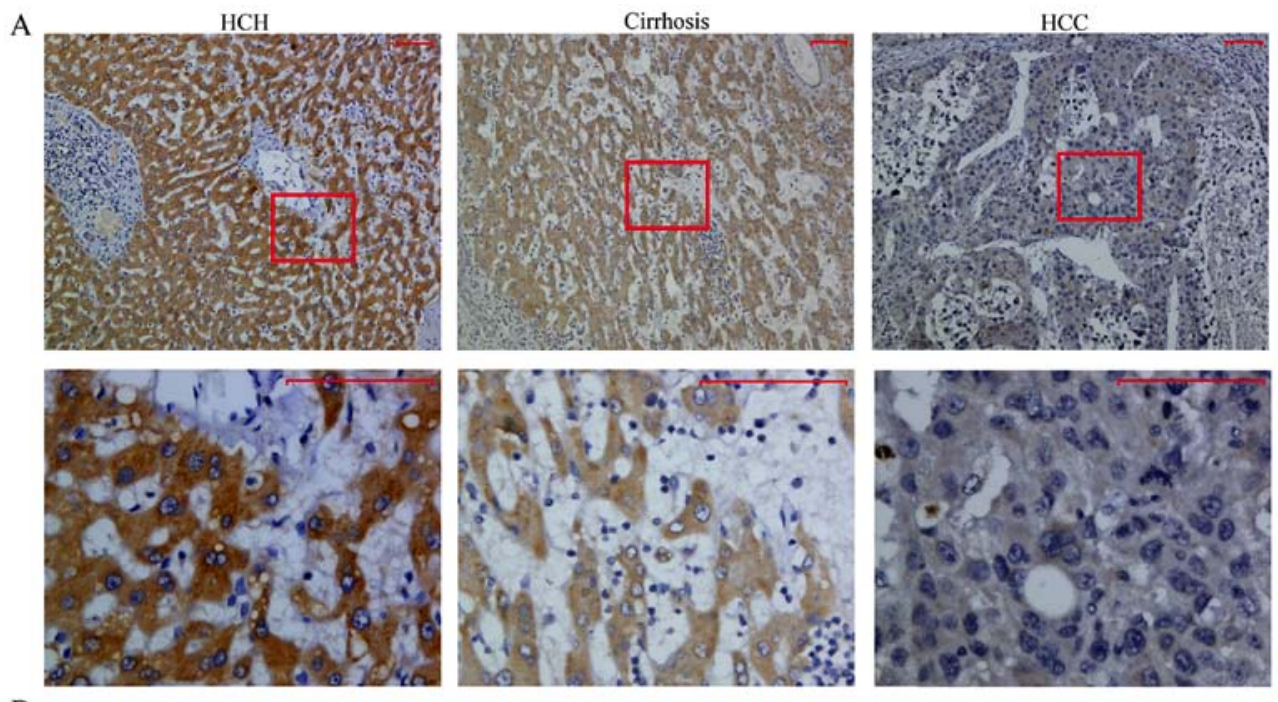

B

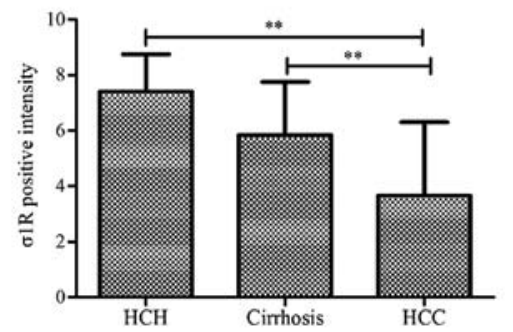

Figure 1. Immunohistochemical analysis of o1R in benign hepatic tissue of $\mathrm{HCH}$, cirrhotic cancer-adjacent liver tissues, and malignant $\mathrm{HCC}$ tissues. (A) $\sigma 1 \mathrm{R}$ expression in the progression from benign hepatic tissue to HCC. The staining was mainly located in the cytoplasm. In HCH tissues, the immunostaining of olR was intense and well-distributed compared with that in hepatic cirrhosis. Weak or negative staining was observed in HCC. Scale bars, $50 \mu \mathrm{m}$. (B) Rates of positive $\sigma 1 \mathrm{R}$ expression in $\mathrm{HCH}$, hepatic cirrhosis and $\mathrm{HCC}$. Statistically significant differences were observed between $\mathrm{HCH}$ and $\mathrm{HCC}\left({ }^{* *} \mathrm{P}<0.01\right)$, and between hepatic cirrhosis and HCC $(* * \mathrm{P}<0.01)$, respectively. o1R, sigma-1 receptor; HCC, hepatocellular carcinoma; $\mathrm{NCH}$, hepatic cavernous hemangioma.

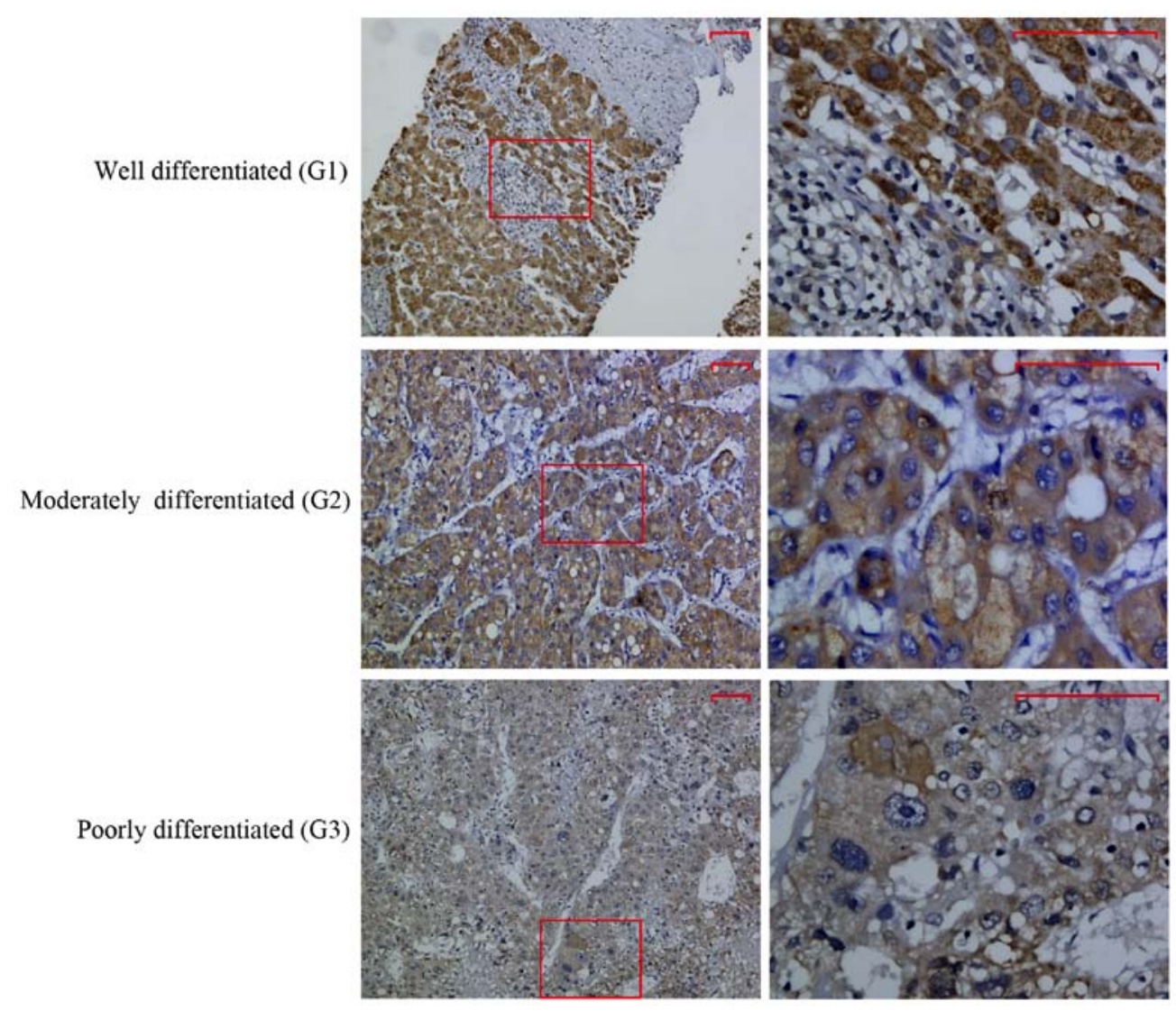

Figure 2. Immunohistochemical staining of o1R in HCC according to the degree of differentiation (grades 1, 2 and 3). The staining of o1R was found to gradually weaken with increased differentiation grade. Scale bars, $50 \mu \mathrm{m}$. o1R, sigma-1 receptor; HCC, hepatocellular carcinoma. 

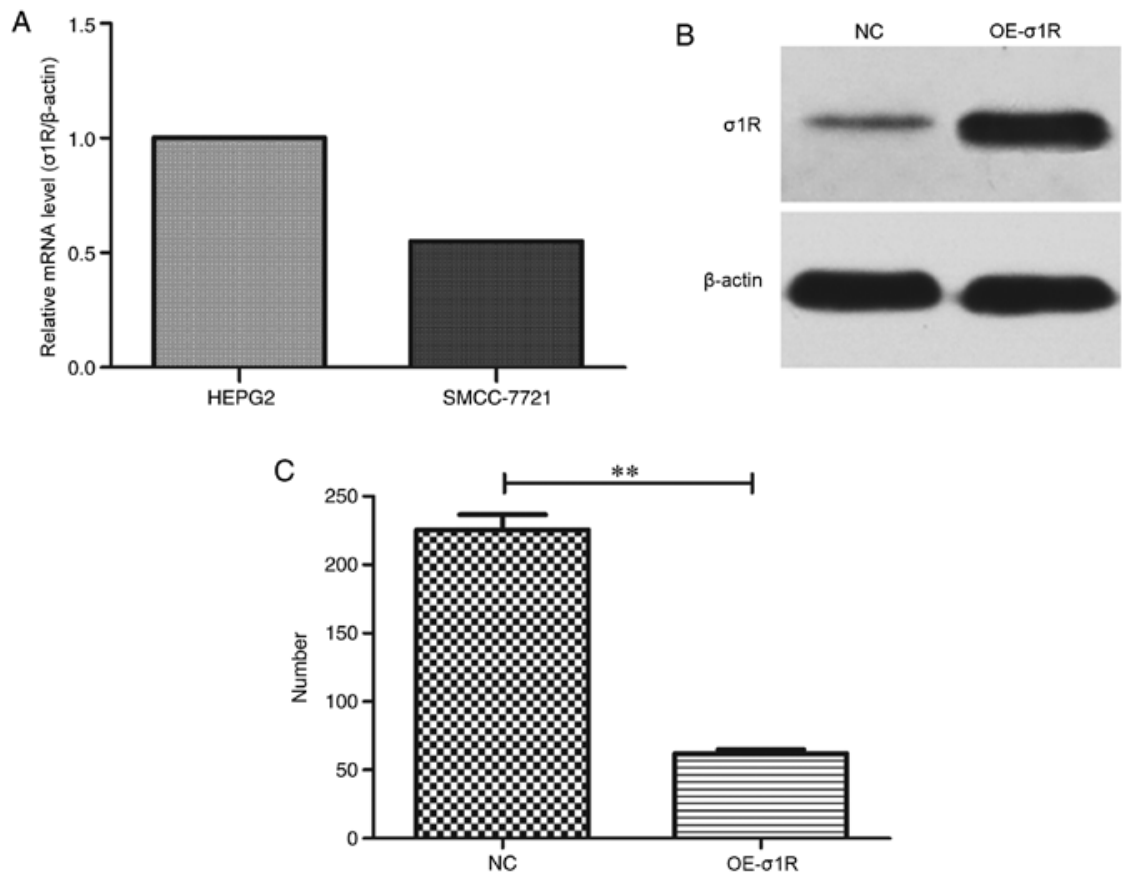

Figure 3. mRNA and protein expression levels of $\sigma 1 \mathrm{R}$ in hepatic malignant tumor cell lines. (A) $\sigma 1 \mathrm{R}$ mRNA level in HepG2 and SMCC-7721 cell lines. Expression of o1R mRNA was measured by RT-qPCR in the indicated cell lines. The constitutively expressed $\beta$-actin gene was used as an internal control. (B) Overexpression of $\sigma 1 \mathrm{R}(\mathrm{OE}-\sigma 1 \mathrm{R})$ protein in HepG2 cells. $\sigma 1 \mathrm{R}$ protein expression was analyzed by western blotting in control-transfected (negative control; NC) and o1R-GV141-transfected HepG2 cells after 4 days of cell culture. (C) Confirmation of o1R overexpression in HepG2 cells. HepG2 cells were transfected with $\sigma 1 \mathrm{R}-\mathrm{GV} 141$ or NC lentivirus and $\sigma 1 \mathrm{R}$ protein levels were analyzed by western blotting; ${ }^{* *} \mathrm{P}<0.01$. $\beta$-actin was used as an internal control. $\sigma 1 \mathrm{R}$, sigma-1 receptor; HCC, hepatocellular carcinoma. o1R, sigma-1 receptor.
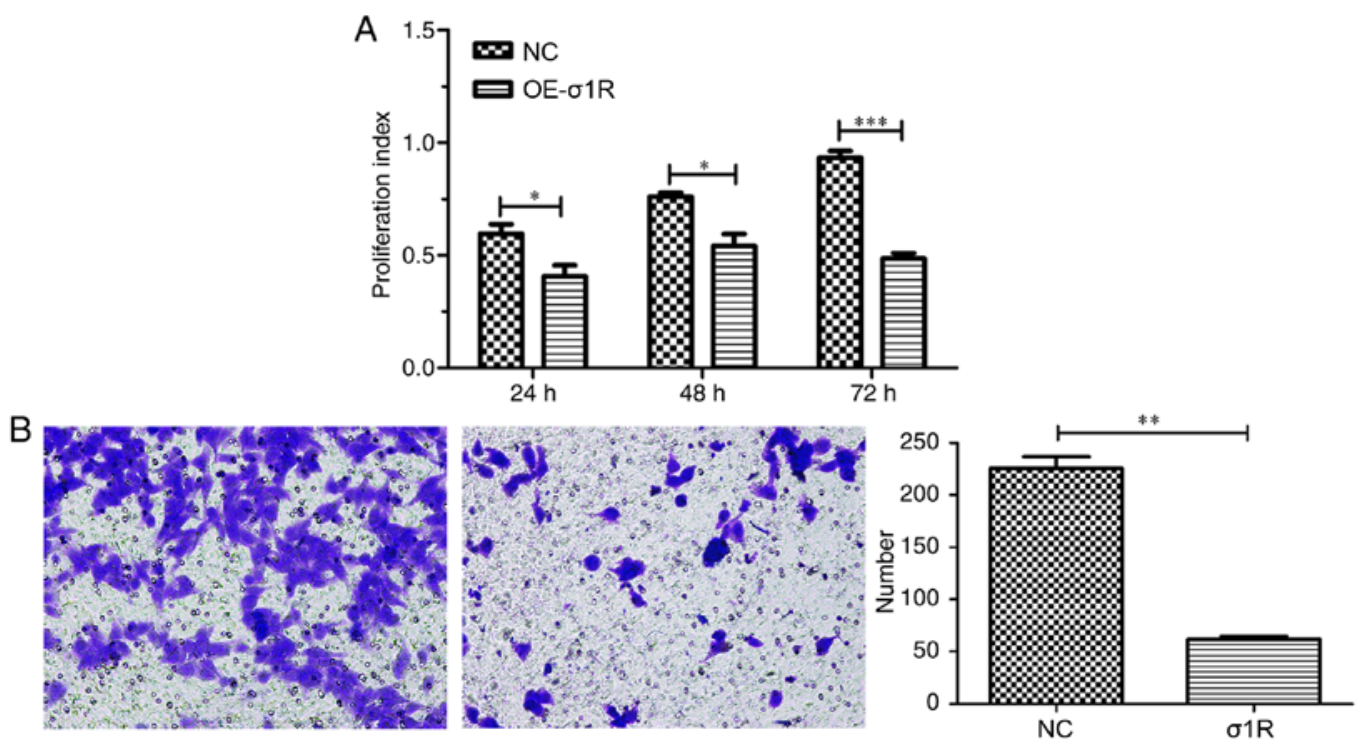

Figure 4. Overexpression o1R suppresses cell proliferation and migration in HepG2 cells. (A) The proliferation index of o1R-GV141-transfected HepG2 cells compared with the control group (NC) was determined by MTT assay; ${ }^{*} \mathrm{P}<0.05,{ }^{* * * *} \mathrm{P}<0.001$. (B) A similar trend was observed in the cell migration assay. Bright field microscopic images are shown (magnification, $\mathrm{x} 200$ ); ${ }^{* *} \mathrm{P}<0.01$. Data are shown as the mean $\pm \mathrm{SD}$. $\sigma 1 \mathrm{R}$, sigma-1 receptor.

the NC-transfected cells $(\mathrm{P}<0.05)$, and the inhibitory effect on the third day was more obvious compared with that on the first day of cell incubation $(\mathrm{P}<0.001)$. Furthermore, a Transwell migration assay was performed to determine the effect of $\sigma 1 \mathrm{R}$ overexpression on the invasive ability of HepG2 cells in vitro. The results showed that $\sigma 1 \mathrm{R}$ overexpression in HepG2 cells caused a significant reduction in migration compared with the $\mathrm{NC}$ cells (Fig. 4B; $\mathrm{P}<0.01$ ). Thus, it was demonstrated that the overexpression of o1R suppressed the proliferation and migration of HepG2 cells.

olR overexpression causes cell cycle arrest in the G1 phase and induces apoptosis in HepG2 cells. As changes in cell numbers may result from arrest of cell cycle progression or induction of apoptosis, both were analyzed by flow cytometry. As shown in Fig. 5A, for HepG2 cells, the o1R-overexpressing 

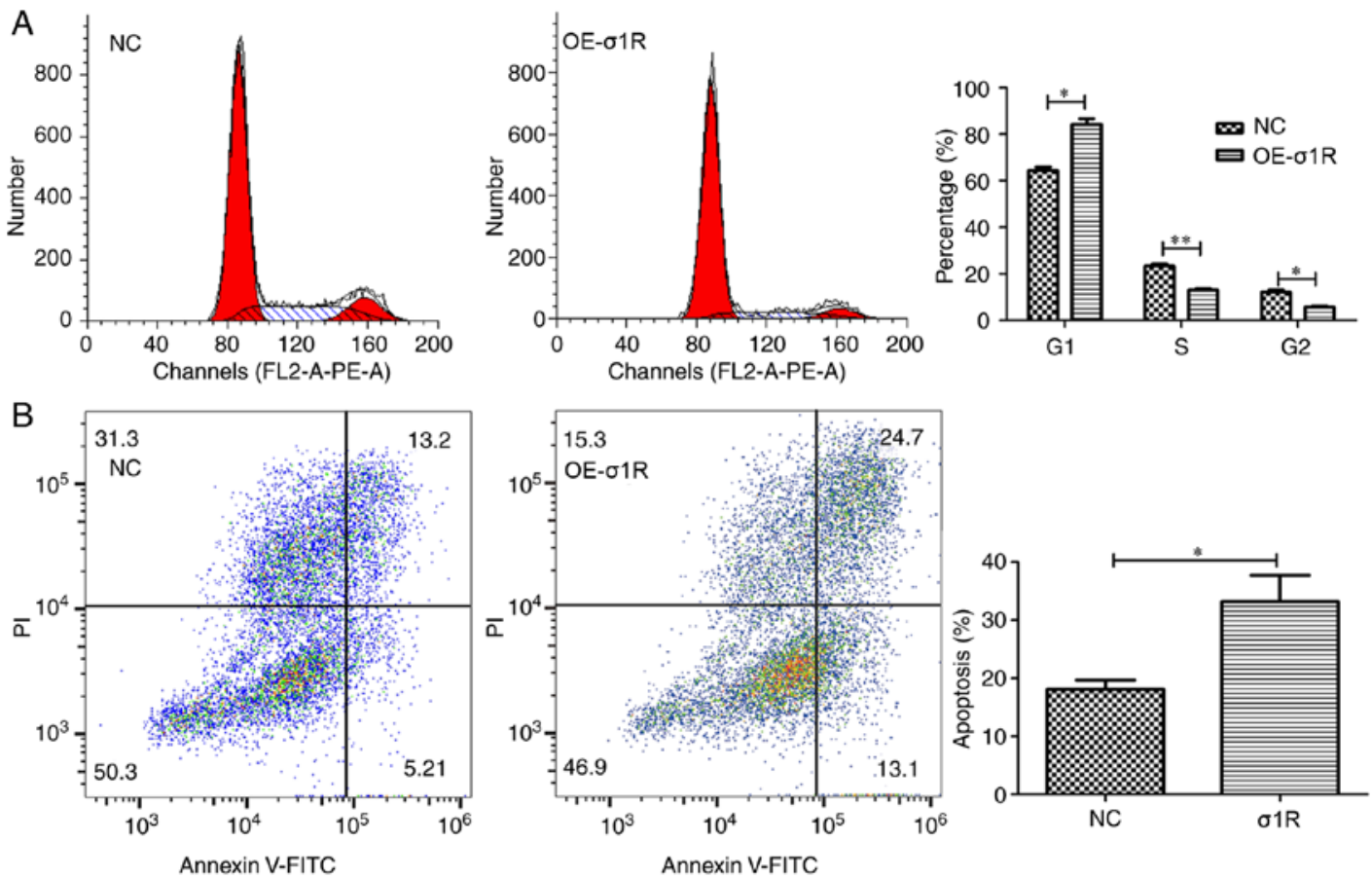

Figure 5. Overexpression o1R leads to cell cycle arrest and induces cell apoptosis. (A) Flow cytometric analysis of cell cycle distribution revealed that overexpression of $\sigma 1 \mathrm{R}$ induced cell cycle arrest at the G1 phase; ${ }^{*} \mathrm{P}<0.05,{ }^{* *} \mathrm{P}<0.01$. (B) Cell apoptosis was determined by Annexin $\mathrm{V}$ staining and flow cytometry. The apoptosis of HepG2 cells was induced by $\sigma 1 \mathrm{R}-\mathrm{GV} 141$ transfection; ${ }^{*} \mathrm{P}<0.05$. Data are shown as the mean $\pm \mathrm{SD}$. $\sigma 1 \mathrm{R}$, sigma-1 receptor.
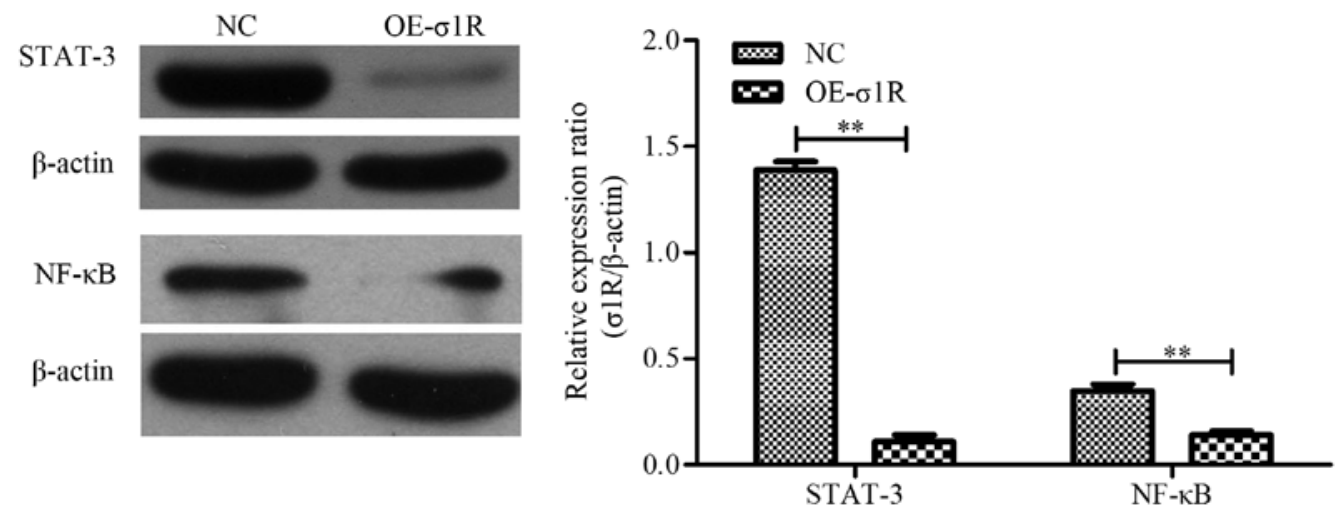

Figure 6. Overexpression of $\sigma 1 \mathrm{R}$ suppresses the expression of STAT-3 and NF-kB. HepG2 cells were transfected with $\sigma 1 \mathrm{R}$-GV141 lentivirus for 3 days and subjected to western blotting with the indicated antibodies. $\beta$-actin was used as a loading control; ${ }^{* *} \mathrm{P}<0.01$. Data are shown as the mean $\pm \mathrm{SD}$. $\sigma 1 \mathrm{R}$, sigma- 1 receptor.

group and NC group exhibited the following cell cycle distributions: G1 phase, $84.17 \pm 4.19$ vs. $64.42 \pm 2.66 \%$, respectively; S phase, $13.00 \pm 1.30$ vs. $23.40 \pm 1.37 \%$, respectively; and $\mathrm{G} 2 / \mathrm{M}$ phase, $5.59 \pm 0.81$ vs. $12.17 \pm 1.51 \%$, respectively. The results showed a significant decrease in the proportion of cells in the $S$ phase $(P<0.01)$ or $G 2 / M$ phase $(P<0.05)$, and an increase in the proportion of cells in $\mathrm{G} 1$ phase $(\mathrm{P}<0.05)$ in the o1R-overexpressing group compared with the $\mathrm{NC}$ group, suggesting that $\sigma 1 \mathrm{R}$ overexpression led to cell cycle arrest in G1 phase. The ability to resist apoptosis is an important feature of tumor cells (21). In the present study, the apoptosis analysis following Annexin $\mathrm{V}$ staining showed that the apoptotic rate of o1R-overexpressing cells was significantly increased with respect to the control group (Fig. 5B; $33.20 \pm 4.52$ vs. $18.13 \pm 1.57 \% ; \mathrm{P}<0.05)$. These data indicated that $\sigma 1 \mathrm{R}$ may be associated with apoptosis in HMT.
olR overexpression inhibits STAT-3 and $N F-\kappa B$ expression. To explore the molecular mechanisms underlying the involvement of $\sigma 1 \mathrm{R}$ in HMT development, we analyzed the effect of o1R on oncogenic signaling pathways. Western blotting showed that STAT-3 and NF-kB were decreased in HepG2 cells overexpressing o1R (Fig. 6; $\mathrm{P}<0.01$ ). These results suggested that the upregulation of $\sigma 1 \mathrm{R}$ may be responsible for STAT-3 and NF- $\mathrm{KB}$ downregulation in the context of HepG2 cell proliferation, apoptosis and migration.

\section{Discussion}

HCC is a type of malignant tumor associated with rapid progression and a poor survival rate (3). Although there have been extensive studies on HMT, poor prognosis and the limited value of established prognostic markers have prompted 
researchers to search for new biomarkers that are able to predict the prognosis and act as possible treatment targets in patients with HMT. Sigma-1 receptor ( $\sigma 1 \mathrm{R})$ was first discovered in the nervous system by Martin et al (7), although its expression has since been identified in other organs, including the liver, kidneys, lungs and gonads (14,17). More recently, studies have found that $\sigma 1 \mathrm{R}$ is highly expressed in various cancer tissues of neural and non-neural origins $(12,15,16,22,23)$, and the upregulation of $\sigma 1 \mathrm{R}$ has been reported to be associated with biological behavior, such as proliferation, adhesion and cell death, in tumors $(13,24)$. However, the expression and biological significance of $\sigma 1 \mathrm{R}$ in HMT remain unknown.

A novel finding in the present study was that $\sigma 1 \mathrm{R}$ was expressed at low levels in HCC, and that there was a statistically significant difference between its expression levels in benign hepatic tissue and HCC $(\mathrm{P}<0.01)$. The decreased expression of $\sigma 1 \mathrm{R}$ in $\mathrm{HCC}$ was an interesting phenomenon, which was inconsistent with former studies in other tumor types $(16,18,25)$. We considered that this contradiction may indicate a different molecular biological function in HCC compared with other tumor types. It has been reported that certain narcotic drugs and oxygen and glucose deprivation are important factors in inducing o1R expression $(26,27)$. The liver is an organ that is central to metabolism and produces a wide range of chemicals essential to bodily functioning. External and internal factors may interact with HCC tumor cells to regulate the expression of $\sigma 1 \mathrm{R}$.

Histological differentiation is a significant factor in estimating the prognosis of cancer patients. Patients with high-grade HCC often have a poor prognosis. In the present study, a significant inverse correlation was observed between $\sigma 1 \mathrm{R}$ expression and the grade of differentiation of $\mathrm{HCC}(\mathrm{r}=-0.424, \mathrm{P}=0.021)$, and HCC cases with a high level of o1R expression were more likely to have low grade disease. Therefore, we speculated that o1R may play a role in the initiation or progression of $\mathrm{HCC}$, and particularly in histological differentiation.

In the present study, lentivirus-GV141-mediated o1R overexpression markedly inhibited HMT cell proliferation and migration in vitro; the cell proliferation rate and migratory ability in the o1R-GV141 group were significantly decreased or decelerated compared with the NC lentivirus-transfected group. Furthermore, o1R overexpression induced cell cycle arrest in the G1 phase and promoted cell apoptosis. These findings demonstrate that the downregulation of $\sigma 1 \mathrm{R}$ has an important effect on HMT cell proliferation and migration, and that it may serve as a potential predictive factor and therapeutic target in the treatment of HMT.

The scientific basis underlying the inhibitory effect of $\sigma 1 \mathrm{R}$ overexpression on tumor proliferation is an important aspect for further research. Ion channels are considered to play a crucial role in many tumor types (16). Aydar et al found that Kv1.4 and Kv1.5 ion channels were highly sensitive to o1R ligands in the presence of $\sigma 1 \mathrm{R}$, while the modulation was weak in the absence of o1R in Xenopus oocytes, which suggested that o1R may form a functional complex with the expressed ion channels (10). In addition, Spruce et al (28) considered that o1R ligands may be involved in the calcium-dependent activation of phospholipase $\mathrm{C}$ and concomitant calcium-independent inhibition of phosphatidylinositol 3'-kinase pathway signaling in some cancer cells.
Signal transducer and activator of transcription-3 (STAT-3), a member of the STAT family, is commonly activated in human epithelial cancers $(29,30)$. Constitutive activation of STAT3 contributes to oncogenesis and progression, including increased cell proliferation and survival (31). Wu et al (32) demonstrated that increased STAT-3 expression was correlated with higher tumor stage and decreased patient survival in cases of HMT.

Nuclear factor $-\kappa \mathrm{B}(\mathrm{NF}-\kappa \mathrm{B})$ is a well-known nuclear transcription factor that regulates the expression of a variety of genes critical for the regulation of apoptosis (33). The activation of $\mathrm{NF}-\kappa \mathrm{B}$ induces antiapoptotic gene expression to promote cell survival. In the present study, we found that the expression levels of STAT- 3 and NF- $\kappa$ B were decreased in o1R-overexpressing HepG2 cells relative to the NC group. Our findings preliminarily indicate that $\sigma 1 \mathrm{R}$ overexpression may suppress HepG2 cell proliferation and migration through inactivation of STAT-3 and NF- $\kappa$ B.

In summary, the present findings indicate that $\sigma 1 \mathrm{R}$ is decreased in HCC and is closely correlated with histological differentiation. The overexpression of $\sigma 1 \mathrm{R}$ suppressed cell proliferation, inhibited cell migration and induced cell cycle arrest and cell apoptosis in HepG2 hepatoblastoma cells. Therefore, we hypothesized that o1R has an important role in promoting $\mathrm{HCC}$ cell differentiation. Elucidation of the functions and detailed mechanisms of $\sigma 1 \mathrm{R}$ in regulating HMT tumorigenesis and progression are the subjects of our ongoing research.

\section{Acknowledgements}

The present study was supported by a grant from the Natural Science Foundation of Shandong Province (grant no. ZR2014HP014).

\section{References}

1. Bell D, Ranganathan S, Tao J and Monga SP: Novel advances in understanding of molecular pathogenesis of hepatoblastoma: A Wnt/ $\beta$-catenin perspective. Gene Expr 17: 141-154, 2017.

2. Jemal A, Bray F, Center MM, Ferlay J, Ward E and Forman D: Global cancer statistics. CA Cancer J Clin 61: 69-90, 2011.

3. Liu S, Li N, Yu X, Xiao X, Cheng K, Hu J, Wang J, Zhang D, Cheng $S$ and Liu S: Expression of intercellular adhesion molecule 1 by hepatocellular carcinoma stem cells and circulating tumor cells. Gastroenterology 144: 1031-1041, 2013.

4. McGuire S: World Cancer Report 2014. Geneva, Switzerland: World Health Organization, International agency for research on cancer, WHO Press, 2015. Adv Nutr 7: 418-419, 2016.

5. El-Serag HB and Rudolph KL: Hepatocellular carcinoma: Epidemiology and molecular carcinogenesis.Gastroenterology 132: 2557-2576, 2007.

6. Stravitz RT, Heuman DM, Chand N, Sterling RK, Shiffman ML, Luketic VA, Sanyal AJ, Habib A, Mihas AA, Giles HC, et al: Surveillance for hepatocellular carcinoma in patients with cirrhosis improves outcome. Am J Med 121: 119-126, 2008.

7. Martin WR, Eades CG, Thompson JA, Huppler RE and Gilbert PE: The effects of morphine- and nalorphine-like drugs in the nondependent and morphine-dependent chronic spinal dog. J Pharmacol Exp Ther 197: 517-532, 1976.

8. Walker JM, Bowen WD, Walker FO, Matsumoto RR, de Costa B and Rice KC: Sigma receptors: Biology and function. Pharm Rev 42: 355-402, 1990.

9. Hanner M, Moebius FF, Flandorfer A, Knaus HG, Striessnig J, Kempner E and Glossmann H: Purification, molecular cloning,

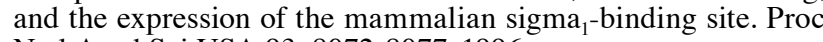
Natl Acad Sci USA 93: 8072-8077, 1996. 
10. Aydar E, Palmer CP, Klyachko VA and Jackson MB: The sigma receptor as a ligand-regulated auxiliary potassium channel subunit. Neuron 34: 399-410, 2002.

11. Hayashi T and Su TP: Sigma-1 receptor chaperones at the ER-mitochondrion interface regulate $\mathrm{Ca}^{2+}$ signaling and cell survival. Cell 131: 596-610, 2007.

12. Crawford KW and Bowen WD: Sigma-2 receptor agonists activate a novel apoptotic pathway and potentiate antineoplastic drugs in breast tumor cell lines. Cancer Res 62 : 313-322, 2002.

13. Brent PJ and Pang GT: Sigma binding site ligands inhibit cell proliferation in mammary and colon carcinoma cell lines and melanoma cells in culture. Eur J Pharmacol 278: 151-160, 1995.

14. Hellewell SB, Bruce A, Feinstein G, Orringer J, Williams W and Bowen WD: Rat liver and kidney contain high densities of sigma 1 and sigma 2 receptors: Characterization by ligand binding and photoaffinity labeling. Eur J Pharmacol 268: 9-18, 1994.

15. Vilner BJ, John CS and Bowen WD: Sigma-1 and sigma-2 receptors are expressed in a wide variety of human and rodent tumor cell lines. Cancer Res 55: 408-413, 1995.

16. Aydar E, Palmer CP and Djamgoz MB: Sigma receptors and cancer: Possible involvement of ion channels. Cancer Res 64: 5029-5035, 2004.

17. Wolfe SA Jr, Culp SG and De Souza EB: Sigma-receptors in endocrine organs: Identification, characterization, and autoradiographic localization in rat pituitary, adrenal, testis, and ovary. Endocrinology 124: 1160-1172, 1989.

18. Xu QX, Li EM, Zhang YF, Liao LD, Xu XE, Wu ZY, Shen JH and Xu LY: Overexpression of sigmal receptor and its positive associations with pathologic TNM classification in esophageal squamous cell carcinoma. J Histochem Cytochem 60: 457-466, 2012.

19. López-Terrada D, Cheung SW, Finegold MJ and Knowles BB: Hep G2 is a hepatoblastoma-derived cell line. Hum Pathol 40: 1512-1515, 2009.

20. Milner AE, Levens JM and Gregory CD: Flow cytometric methods of analyzing apoptotic cells. Methods Mol Biol 80: 347-354, 1998.

21. Fernald $\mathrm{K}$ and Kurokawa M: Evading apoptosis in cancer. Trends Cell Biol 23: 620-633, 2013.

22. Thomas GE, Szücs M, Mamone JY, Bem WT, Rush MD, Johnson FE and Coscia CJ: Sigma and opioid receptors in human brain tumors. Life Sci 46: 1279-1286, 1990.
23. Bem WT, Thomas GE, Mamone JY, Homan SM, Levy BK, Johnson FE and Coscia CJ: Overexpression of sigma receptors in nonneural human tumors. Cancer Res 51: 6558-6562, 1991.

24. Aydar E, Onganer P, Perrett R, Djamgoz MB and Palmer CP: The expression and functional characterization of sigma (sigma) 1 receptors in breast cancer cell lines. Cancer Lett 242: 245-257, 2006.

25. Crottès D, Guizouarn H, Martin P, Borgese F and Soriani O: The sigma-1 receptor: A regulator of cancer cell electrical plasticity? Front Physiol 4: 175, 2013.

26. Guitart X, Codony X and Monroy X: Sigma receptors: Biology and therapeutic potential. Psychopharmacology 174: 301-319, 2004.

27. Ruscher K, Shamloo M, Rickhag M, Ladunga I, Soriano L, Gisselsson L, Toresson H, Ruslim-Litrus L, Oksenberg D, Urfer R, et al: The sigma-1 receptor enhances brain plasticity and functional recovery after experimental stroke. Brain 134: 732-746, 2011

28. Spruce BA, Campbell LA, McTavish N, Cooper MA, Appleyard MV, O'Neill M, Howie J, Samson J, Watt S, Murray K, et al: Small molecule antagonists of the sigma-1 receptor cause selective release of the death program in tumor and self-reliant cells and inhibit tumor growth in vitro and in vivo. Cancer Res 64: 4875-4886, 2004.

29. Deng JY, Sun D, Liu XY, Pan Y and Liang H: STAT-3 correlates with lymph node metastasis and cell survival in gastric cancer. World J Gastroenterol 16: 5380-5387, 2010.

30. Kim HS, Park YH, Lee J, Ahn JS, Kim J, Shim YM, Kim JH, Park K, Han J and Ahn MJ: Clinical impact of phosphorylated signal transducer and activator of transcription 3, epidermal growth factor receptor, p53, and vascular endothelial growth factor receptor 1 expression in resected adenocarcinoma of lung using tissue microarray. Cancer 116: 676-685, 2010.

31. Kanda N, Seno H, Konda Y, Marusawa H, Kanai M, Nakajima T, Kawashima T, Nanakin A, Sawabu T, Uenoyama Y, et al: STAT3 is constitutively activated and supports cell survival in association with survivin expression in gastric cancer cells. Oncogene 23: 4921-4929, 2004

32. Wu WY, Li J, Wu ZS, Zhang CL, Meng XL and Lobie PE: Prognostic significance of phosphorylated signal transduce and activator of transcription 3 and suppressor of cytokine signaling 3 expression in hepatocellular carcinoma. Exp Ther Med 2: 647-653, 2011.

33. Karin M: Nuclear factor-kappaB in cancer development and progression. Nature 441: 431-436, 2006. 